\title{
Detecting Contagion Effects During The Subprime Crisis Using Different VAR Size Models: Comparison Between OLS And Bayesian Shrinkage
}

Olfa Kaabia, University of Paris Ouest Nanterre La Defense, France Ilyes Abid, University of Paris Ouest Nanterre La Defense, France

\begin{abstract}
This paper assesses the performance in terms of forecast and structural analysis of different sizes of VAR models while studying contagion effects during the subprime crisis. We compare VAR models of different sizes: a standard VAR estimated by OLS, and a MEDIUM and LARGE VARs estimated by a Bayesian shrinkage procedure.
\end{abstract}

Using a large database containing national macroeconomic, financial, and trade dynamic variables for 17 OECD countries, we study contagion effects on U.S key variables and OECD housing markets over the period of the subprime crisis.

Our paper unearths that the smallest specification outperforms the largest one, in terms of forecast accuracy and structural analysis. Our results reveal that the SMALL and MEDIUM VARs produce qualitatively similar results; however, the MEDIUM VAR permits us to obtain the responses of a large set of variables and so provides a more comprehensive picture of the effects of the subprime crisis. So, we conclude that the MEDIUM VAR is more successful at extracting pertinent information for a large data set. It appears that dealing with a LARGE VAR provides worst results.

An interesting result that arises is that the standard OLS estimation is interesting; however, the Bayesian shrinkage is a useful tool, in the case of an international contagion study, allowing both a more comprehensive picture of the contagion effects as well as a more complete check of the empirical plausibility of the underlying specification.

Keywords: Contagion; Subprime Crisis; OECD Housing Markets; VAR/ BVAR Models and Bayesian Shrinkage

\section{INTRODUCTION}

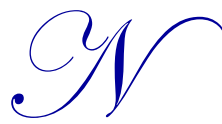

owadays, VAR models are standard tools in macroeconomics, and are widely used for structural analysis. They have the advantage of not imposing restrictions on the parameters, and, hence, provide a very general representation allowing the capture of complex data relationships. Other VAR-type models have been proposed as Structural VARs ${ }^{1}$; however, we always notice the same criticism of the VAR approach, according to the relatively small amount of information used in VARs ${ }^{2}$. This issue has been especially addressed by Bernanke and al. (2005).

\footnotetext{
${ }^{1}$ Introduced by Sims (1980).

2 To conserve degrees of freedom, standard VARs rarely employ more than six to eight variables.
} 
In that sense, many researches propose to add more than eight variables in a VAR model; for instance, the marginal approach proposed by Christiano, Eichenbaum and Evans (1996), or Kim (2001). They define a core set of indicators, and add one variable, or a group of variables, at a time; however, comparison of impulse responses across models is problematic. Moreover, let mention Leeper, Sims, and Zha (1996) who increased the number of variables included by applying Bayesian priors. However, in their study, the VAR systems still contain less than 20 variables. Also, Stock and Watson (2005), and Bernanke and al. (2005) introduced the FAVAR models. The idea is that if a small number of estimated factors effectively summarizes large amounts of information about the economy, then a natural solution to the degrees-of-freedom problem in VAR analyses - which have to be of limited dimensions is to augment the standard VAR with estimated factors. Moreover, Kaabia and Abid (2013) introduced Bayesian techniques in FAVAR model as to better characterize the transmission channels during the Subprime crisis. However, many issues remain unsolved concerning the estimation approach, the number and the nature of the factors.

So our analysis starts from the great criticism of the sparse information set used in the VAR model, which normally does not include more than eight variables to conserve degrees of freedom. In fact, central banks generally use a large information set to analyze the state of the economy before making any decision. In that sense, the VAR approach may exclude important information considered pertinent in the transmission process during turmoil periods. We will study the contagion effects of the subprime crisis which has started in the U.S and spread out to many countries all over the world.

The subprime crisis is not the first turmoil event occurring in the housing markets. Yet, the housing prices boom during the early 2000s has raised many questions, and since then many studies focused on a possible international transmission of housing shocks across countries (Otrok and Terrones, 2004). So, the last subprime crisis has confirmed the fears of possible contagion effects due to liberalization of markets. In fact, since 2006, the decrease of U.S. housing prices, as a result of collapsing residential investments has been followed by a wave of crises, and a sharp decrease in housing prices in other economies. This last crisis, which emerged in the USA in the summer of 2006, was followed by a sharp fall in housing prices in Ireland, New Zealand, Spain, and the United Kingdom. These almost parallel developments provide evidence in favor of a significant correlation across national housing markets.

There appears to be a large degree of co-movements between very different and distant countries. It seems that the U.S. housing boom and bust has spread to other parts of the world, and so confirms that the United States continues to retain its place as the world's principal leading country.

In this paper, we aim at studying contagion effects detected when a local shock affects the propagation mechanism of a large number of OECD variables. In other words, the investigation of contagion effects is to focus on the changes in the transmission mechanisms of shocks, at a critical date. Our analysis is important in terms of policy implications, or even for international investors. The scope of our paper is to contribute to the literature on international transmission.

The idea is to examine the contagion effects of a U.S. housing prices index shock on OECD countries, and to explore which VAR model better reflects the propagation and magnitude of the changes in the transmission processes, so as to reproduce what happened during the subprime crisis. To our knowledge, no paper in the literature has used such comparison to test and model the contagion effects.

Specifically, in our study, we address the following questions:

1. Is it necessary to deal with a large panel of data when studying contagion effects during the subprime crisis?

2. Which VAR model specification does reflect most faithfully what happened in the U.S and OECD countries during the subprime crisis, in terms of forecast and structural analysis?

3. In practice, is Bayesian shrinkage a valid alternative to Ordinary Least Squares (OLS) estimation in the case of international transmission study? 
To answer these questions we choose different sizes of VAR models to characterize such dynamics for the OECD countries in our panel. Also, we build on the results obtained by De Mol, Giannone, and Reichlin (2008) and Bańbura, Giannone and Reichlin (2010) by setting the degree of Bayesian shrinkage in relation to the cross-sectional dimension of the model, so as to compare the three models.

Our main contributions to the existing literature are: First, the novelty of dealing with a Bayesian shrinkage procedure allows us to study the impact of U.S. housing prices index shock on the many OECD financial and economic variables included in our dataset in the form of impulse responses. This is particularly relevant given the most recent crisis which has been characterized by sudden shocks of large magnitude. Researchers, investors, and policy analysts are focusing on robust models allowing the reflection of negative effects on many variables in crisis period.

Second, many economic concepts need more than one variable, such as the real activity. So, dealing with a Bayesian shrinkage approach, i.e. the MEDIUM/ LARGE Bayesian VARs may be, a priori, a solution to capture many concepts.

Third, another advantage of using this type of VAR models specifications is that impulse responses can be observed both for variables included only in a small VAR, and for large key variables. If housing markets are contagious, economic policy should focus on structural reforms ensuring a stable domestic market in order to limit the amplification of shocks between housing markets.

Finally, using different VARs specifications allows us to compare our results to previous findings in terms of forecast and structural analysis, in the case of international transmission process.

Dealing with a huge database, we will study the impact of the U.S. housing prices index shock, and analyze the contagion effects on U.S key variables and OECD housing prices. Our database includes the 204 monthly following variables: real GDP, personal consumption, short-term and long-term interest rates, all share prices index, effective exchange rates, housing prices index, consumer price index, unemployment rate, export and import prices, for each of the seventeen considered OECD countries, over the period of 1980: M1 - 2006: M6. ${ }^{3}$ It is worth emphasizing that this sample is larger and more international than related studies. ${ }^{4}$

We find that the smallest specification outperforms the largest one in terms of forecast accuracy, and structural analysis. Moreover, the SMALL and MEDIUM VARs produce qualitatively similar results suggesting that the MEDIUM VAR is more successful at extracting pertinent information for a large data set. So, we conclude that the MEDIUM VAR is preferable.

Also, the standard OLS estimation is interesting; however, the Bayesian shrinkage is a useful tool, in the case of an international contagion study, providing both a more comprehensive picture of the contagion effects as well as a more complete check of the empirical plausibility of the underlying specification.

The rest of the paper is structured as follows: Section 2 exposes the empirical framework. Section 3 describes the data and presents the results in terms of forecast and structural analysis. Section 4 draws the appropriate conclusions.

\section{EMPIRICAL FRAMEWORK}

We propose to study contagion effects in the case of simulating the last subprime crisis, using different sizes of VAR models. So, we evaluate forecasting accuracy, and perform a structural exercise on the effect of a U.S. housing shock using different sizes of VARs: a SMALL one, estimated by OLS as well as a MEDIUM VAR, and a LARGE one estimated by Bayesian shrinkage.

\footnotetext{
${ }^{3}$ It is considered as a broad measure of financial and economic co-movements.

${ }^{4}$ For example, that of Stock and Watson (2005), or even that of De Bandt and Malik (2010).
} 
In this section, first, we follow standard recommendations in the Bayesian literature, and build on the results of De Mol, Giannone, and Reichlin (2008), and Bańbura, Giannone and Reichlin (2010) by coping with the curse of dimensionality using Bayesian shrinkage via the imposition of priors. Second, we evaluate the forecast performance of different VAR model sizes. And finally, we deal with a structural analysis and make the impulse responses.

\subsection{Setting Priors}

Let a VAR model with $p$ lags, $\operatorname{VAR}(p)$, be as follows:

$Y_{t}=c+A_{1} Y_{t-1}+\cdots+A_{p} Y_{t-p}+u_{t}$

where $Y_{t}=\left(y_{1, t}, \ldots, y_{n, t}\right)^{\prime}, c=\left(c_{1}, \ldots, c_{n}\right)^{\prime}$ is a vector of constants; $A_{1}, \ldots, A_{p}$ are the autoregressive $(n \times n)$ matrices and $u_{t}$ are independent $N(0, \psi)$ errors.

The Bayesian methods combine likelihood function with prior may lead to a valid posterior density even if some parameters are not identified in the likelihood function. However, prior information becomes increasingly important as the number of parameters increases relatively to sample size. In this case, priors on the parameters ${ }^{5}$ $A_{1}, \ldots, A_{p}$ and the residual covariance matrix, $\psi$, should be set. In the literature, many priors are suggested. For a complete review of the existing priors, the reader can refer to Koop (2010).

We follow the standard procedure developed by Litterman (1986) for the VAR coefficients priors. Then, we take into account the modifications proposed by Kadiyala and Karlsson (1997), and Sims and Zha (1998) for the residual covariance matrix priors.

First, according to Litterman (1986), a $\operatorname{VAR}(p)$ can be considered as "centered" equations around the random walk with drift as follows:

$Y_{t}=c+Y_{t-1}+u_{t}$

The idea suggested by Litterman is to shrink all VAR coefficients towards zero except for coefficients on own lags of each dependent variable. The latter are either set to one (for variables which exhibit substantial persistence), or zero (for variables which do not).

So Litterman assumes that the Minnesota prior beliefs ${ }^{6}$ are:

$E\left[\left(A_{k}\right)_{i j}\right]=\left\{\begin{array}{ll}\delta_{i} & \text { if } j=i, k=1 \\ 0 & \text { otherwise }\end{array} ; V\left[\left(A_{k}\right)_{i j}\right]= \begin{cases}\frac{\lambda^{2}}{k^{2}} & \text { if } j=i \\ \vartheta \frac{\lambda^{2}}{k^{2}} \frac{\sigma_{i}^{2}}{\sigma_{j}^{2}} & \text { otherwise }\end{cases}\right.$

The coefficients $A_{1}, \ldots, A_{p}$ are assumed to be a priori independent and normally distributed. Also, the hyper parameters $\lambda$ and $\vartheta$ control the overall tightness of the prior distribution around the random walk or white noise, and govern the relative importance of the prior beliefs with respect to the information contained in the data.

\footnotetext{
${ }^{5}$ The prior on the intercept, $c$, is diffuse.

${ }^{6}$ The reader can refer to Litterman (1986) for more details concerning the setting and hypothesis of each parameter. 
More precisely, if $\lambda=0$, the posterior equals the prior and the data do not influence the estimates. If $\lambda=\infty$, the posterior expectations coincide with the OLS estimates. In the rest of the paper, we will choose $\lambda$ in relation to the size of the VAR model. As the number of variables increases, the parameters should be shrunk some more in order to avoid overfitting.

The parameter $k$ is the lag length and the ratio $1 / k^{2}$ gives the rate at which prior variance decreases with increasing lag length. Also, $\sigma_{i}^{2} / \sigma_{j}^{2}$ reflects the different scale and variability of the data.

Second, according to Kadiyala and Karlsson (1997), and Robertson and Tallman (1999), Litterman's assumption of fixed, and diagonal residual covariance matrix is somewhat unrealistic; that is why they impose a Normal Inverted Wishart prior which retains the principles of the Minnesota prior. Also, this assumption is problematic in the case of the structural analysis, where it is necessary to take into account possible correlation among the residual of different variables.

Consequently, we follow Kadiyala and Karlsson (1997), and Robertson and Tallman (1999) who propose to deal with the matrix form of a $\operatorname{VAR}(p)$ model given by:

$Y=X \beta+U$

where $Y=\left(Y_{1}, \ldots, Y_{T}\right)^{\prime}$ is a $(T \times n)$ matrix. $X=\left(X_{1}, \ldots, X_{T}\right)^{\prime}$ is a $(T \times K)$ matrix, with $X_{t}=\left(1, y_{t-1}^{\prime}, \ldots, y_{t-p}^{\prime}\right)^{\prime}$ and $K=(1+n p)$ since each row contains $p$ lags for each dependent variable, and an intercept. Also, $\beta=\left(c, A_{1}, \ldots, A_{p}\right)^{\prime}$ is the $(K \times n)$ matrix of coefficients and $U=\left(u_{1}, \ldots, u_{T}\right)^{\prime}$ is a $(T \times n)$ residual matrix. The Normal Inverted Wishart prior has the form:

$$
\left\{\begin{array}{l}
\operatorname{vec}(\beta) \mid \psi \sim N\left(\operatorname{vec}\left(\beta_{0}\right), \psi \otimes \Omega_{0}\right) \\
\psi \sim i W\left(\mathrm{~S}_{0}, \alpha_{0}\right)
\end{array}\right.
$$

where the prior parameters $\beta_{0}, \Omega_{0}, \mathrm{~S}_{0}$ and $\alpha_{0}$ are chosen so that prior expectations, and variances of $\beta$ coincide with those implied by equation (3), and the expectation of $\psi$ is equal to the fixed residual covariance matrix $\sum$ of the Minnesota prior ${ }^{7}$.

In order to match the Minnesota moments in equation (3), and implement the prior of equation (5), it is necessary to add dummy variables as follows:

$Y^{*}=X^{*} \beta+U^{*}$

where $Y^{*}=\left(Y^{\prime}, Y_{d}^{\prime}\right) ; X^{*}=\left(X^{\prime}, X_{d}^{\prime}\right) ; U^{*}=\left(U^{\prime}, U_{d}^{\prime}\right)$ and the dummy observations $Y_{d}$ and $X_{d}$ are:

\footnotetext{
${ }^{7}$ See Kadiyala and Karlsson (1997) for more details.
} 


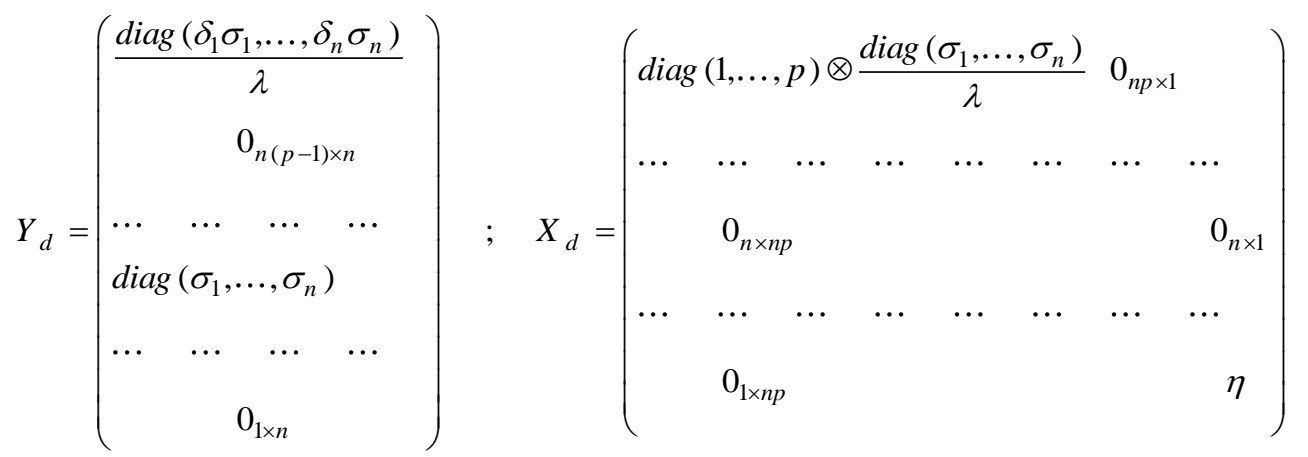

So we obtain that $\beta_{0}=\left(X_{d}^{\prime} X_{d}\right)^{-1} X_{d}^{\prime} Y_{d}, \quad \Omega_{0}=\left(X_{d}^{\prime} X_{d}\right)^{-1}, \quad \mathrm{~S}_{0}=\left(Y_{d}-X_{d} \beta_{0}\right)^{\prime}\left(Y_{d}-X_{d} \beta_{0}\right) \quad$ and $\alpha_{0}=T_{d}-K$.

And in that case, the posterior has the form ${ }^{8}$ :

$$
\left\{\begin{array}{l}
\operatorname{vec}(\beta) \mid \psi, Y \sim N\left(\operatorname{vec}(\tilde{\beta}), \psi \otimes\left(X^{*} X^{*}\right)^{-1}\right) \\
\psi \mid Y \sim i W\left(\tilde{\Sigma}, T_{d}+2+T-k\right)
\end{array}\right.
$$

with $\tilde{\beta}=\left(X^{* \prime} X^{*}\right)^{-1} X^{* \prime} Y^{*}$ and $\tilde{\Sigma}=\left(Y^{*}-X^{*} \tilde{\beta}\right)^{\prime}\left(Y^{*}-X^{*} \tilde{\beta}\right)$

So we impose a Normal Inverted Wishart prior which retains the principles of the Minnesota prior under the condition that $\vartheta=1^{9}$.

The posterior expectation of the coefficients coincides with the OLS estimates of the regression of $Y^{*}$ on $X^{*}$. This expression is common in the Bayesian literature, and coincides with the posterior mean for the Minnesota prior.

After setting the priors, we will move to explain how to make the forecast analysis resulting from different VAR specifications.

\subsection{Forecast Analysis}

We compute point forecasts using the posterior mean of the parameters. Let $\hat{A}_{j}^{(\lambda, m)}(\forall j=1, \ldots, p)$ and $\hat{c}^{(\lambda, m)}$ be, respectively, the posterior mean of the autoregressive coefficients, and the constant term of a given model ( $m=S M A L L, M E D I U M$ or LARGE) and parameter $\lambda$. The point estimate of the one-step-ahead forecast is computed as:

$\hat{Y}_{t+1 \mid t}^{(\lambda, m)}=\hat{c}^{(\lambda, m)}+\hat{A}_{1}^{(\lambda, m)} Y_{t}+\cdots+\hat{A}_{p}^{(\lambda, m)} Y_{t-p+1}$

Also, the other forecasts $h$-steps ahead are computed recursively as follows:

${ }^{8}$ To insure the existence of the prior expectation of $\psi$, it is necessary to add an improper prior $\psi \sim|\psi|^{-(n+3) / 2}$. See De Mol, Giannone, and Reichlin (2008) and Bańbura, Giannone and Reichlin (2010), for more details.

${ }^{9}$ See Kadiyala and Karlsson (1997) for more details. 
$\hat{Y}_{t+h \mid t}^{(\lambda, m)}=\left(\hat{y}_{1, t+h \mid t}^{(\lambda, m)}, \ldots, \hat{y}_{n, t+h \mid t}^{(\lambda, m)}\right)$

where $n$ is the number of variables included in the $m$ model and $h$ is the forecast horizon.

Note that in the case of the benchmark model (random walk with drift), the prior restriction is imposed exactly, that is $\lambda=0$ and the corresponding forecasts are denoted by $\hat{Y}_{t+h \mid t}^{(0)}$, and are the same for all the specifications.

In our analysis, we compute $h$-step-ahead forecasts, $\hat{Y}_{T+h T}^{(\lambda, m)}$, using only the information up to time $T$. For a given forecast horizon $h$, in each period $T=T_{0}+H-h, \ldots, T_{1}-h$ where $H$ denotes the longest forecast horizon to be evaluated. $T_{0}$ and $T_{1}$ are, respectively, the beginning and the end of the evaluation sample.

As for the out-of-sample forecast accuracy, we compute the Mean Squared Forecast Error (MSFE) for the variable, $i$, and a horizon $h$ as:

$\operatorname{MSFE}_{i, h}^{(\lambda, m)}=\frac{1}{T_{1}-T_{0}-H+1} \sum_{T=T_{0}+H-h}^{T_{1}-h}\left(\hat{y}_{i, T+h T}^{(\lambda, m)}-y_{i, T+h}\right)^{2}$

And to compare the different specifications, we use the MSFE relative ( $R M S F E$ ) to the benchmark as follows:

$\operatorname{RMSFE}_{i, h}^{(\lambda, m)}=\frac{\operatorname{MSFE}_{i, h}^{(\lambda, m)}}{M S F E_{i, h}^{(0)}}$

We follow De Mol, Giannone, and Reichlin (2008) and Bańbura, Giannone and Reichlin (2010), and set the overall tightness, $\lambda$, to yield a desired average " Fit " for the key variables of interest during the pre-evaluation period, and then keep it fixed for the entire evaluation period. So, $\lambda$ is chosen for a desired " Fit ", and is given by:

$\lambda^{(m)}($ Fit $)=\arg \min _{\lambda} \mid$ Fit $-\frac{1}{5} \sum_{i \in I} \frac{m s f e_{i}^{(\lambda, m)}}{m s f e_{i}^{(0)}} \mid$

in with $I$ represents the variables included in the SMALL VAR model, $m s f e_{i}^{(\lambda, m)}$ is an in-sample one-step-ahead mean squared forecast error evaluated using the training sample $t=1, \ldots, T_{0}-1$, and is given for the number of lags $p$ as follows:

$m s f e_{i}^{(\lambda, m)}=\frac{1}{T_{0}-p-1} \sum_{t=p}^{T_{0}-2}\left(\hat{y}_{i, t+1 \mid t}^{(\lambda, m)}-y_{i, t+1}\right)^{2}$

More precisely, the desired " Fit " coincides with the one obtained by OLS estimation on the VAR model that is for:

$F i t=\left.\frac{1}{5} \sum_{i \in I} \frac{m s f e_{i}^{(\lambda, m)}}{m s f e_{i}^{(0)}}\right|_{\lambda=\infty ; m=V A R}$

In the next section, we will explain how to make the structural analysis resulting from the VAR models. 


\subsection{Structural Analysis}

We follow Stock and Watson (2005) and Bernanke and al. (2005), and divide the variables in the data into two categories: slow and fast-moving variables. This distinction is crucial because it implies that slow-moving variables do not respond contemporaneously to an initial shock. This hypothesis is equivalent to ranging the variable in an exogeneity order.

So, if we note $S_{t}$ as representing the slow variables, $r_{t}$ is the shocked variable, and $Z_{t}$ is the fast-moving variable, we can write $Y_{t}=\left(S_{t}, r_{t}, Z_{t}\right)$.

The Structural VAR is written as follows:

$\hbar_{0} Y_{t}=v+\hbar_{1} Y_{t-1}+\cdots+\hbar_{p} Y_{t-p}+e_{t}$

with $e_{i} \sim W N(0, D)$ and where $v=C^{-1} c, \lambda_{0}=C^{-1}, \lambda_{j}=C^{-1} A_{j} \forall j=1, \ldots, p$ and $e_{t}$ is the linear transformation of the VAR residuals: $e_{t}=\left(e_{1 t}, \ldots, e_{n t}\right)^{\prime}=C^{-1} u_{t}$.

Let the lower diagonal Cholesky matrix of the covariance of the residuals of the reduced form of a VAR be noted $B=C D^{1 / 2}$, with $C D C^{\prime}=E\left[u_{t} u_{t}^{\prime}\right]=\psi$ and $D=\operatorname{diag}(\psi)$.

We follow Gordon and Leeper (1994) by generating draws from the posterior of $\left(A_{1}, \ldots, A_{p}, \psi\right)$. So for each draw, $\psi$, we compute $B, C$ and even $\hbar_{j} \forall j=0, \ldots, p$.

\section{DATA and RESULTS}

\subsection{Data}

Our large international dataset is drawn from Datastream, Eurostat and the Federal Reserve website, FRED - Saint Louis Fed. The data consists of monthly variables from the period 1981M1-2006M6 for 17 OECD countries, namely United States (U.S.), Canada (CAN), Finland (FIN), France (FRA), Germany (ALL), Ireland (IRL), Italy (ITA), Netherlands (NLD), Spain (ESP), Denmark (DNK), Norway (NOR), Sweden (SWE), Switzerland (SWI), United Kingdom (UK), Australia (AUS), Japan (JPN), and New-Zealand (NZL).

Our dataset includes 204 variables, with 12 variables for each of the 17 countries, encompassing a wide range of financial variables (3-Month Interest Rates, 10-Year Interest Rates, Stock Indices and Housing Price Indices, HPI), variables related to real economy (GDP, Personal Consumption, Industrial Production, Unemployment Rates), aggregate price variables (CPI), trade variables (Import and Export of Goods and Services), and Effective Exchange Rates.

All the data are seasonally adjusted, and the variables are measured at constant national prices. As in the literature, interest rates are differenced, and activity variables are logarithmized. More detailed description is provided in the appendix.

Since the subprime crisis has started in the U.S and spread out to many countries all over the world, we will consider the three following VAR specifications:

- $\quad$ SMALL: This is a VAR including three United States key variables (Gross Domestic Product (GDP_USA), Housing Price Index (HPI_USA) and Stock Market Index (SI_USA)). It represents a U.S national VAR model. It will allow us to study the impact of the subprime crisis on the principal U.S key variables. 
- $\quad$ MEDIUM: This is the previous VAR augmented by the sixteen housing price index of the OECD considered countries.

- LARGE: This VAR contains all the considered 204 variables in our database: an international model.

\subsection{RESULTS}

\subsubsection{Forecast Analysis}

In this section, we evaluate the forecast performance of the three U.S key variables included in the three VAR specifications: GDP_USA, HPI_USA and SI_USA, respectively the U.S Gross Domestic Product, the American Housing Price Index, and the U.S Stock Market Index, over the period going from mid-2006 until the end of 2010 .

Note that for the SMALL VAR, we implement information criteria for lag selection and take the optimal lag according to the Bayesian Information Criterion (BIC). The number of lags retained is $p=11$. This choice confirms the one made by Bernanke and al. (2005), indicating that the series are very persistent.

The estimation is based on the sample from 1982:2 to 2006:6, and the results reported are for the same overall shrinkage as given in Table 1.

Table 1: The Value of the Shrinkage Hyper Parameter $\lambda$ for the Three Considered VARs

\begin{tabular}{|l|c|c|c|}
\hline & SMALL & MEDIUM & LARGE \\
\hline$\lambda$ & $\infty$ & 0.1064 & 0.0388 \\
\hline
\end{tabular}

Note: The abbreviations SMALL, MEDIUM and LARGE refer to the VARs with 3, 19 and 204 variables, respectively.

Moreover, to compare models of different sizes, we choose the Bayesian shrinkage hyper parameter in relation with the models dimensions by ensuring that the in-sample " Fit " is constant and equal to 0.7801 .

As the dimension increases, we set the tightness of the prior so that all models have the same in-sample " Fit " as the smallest VAR estimated by OLS. VARs.

Also, we report, in Table 2, the RMSFE for the five OECD housing price indices for the three different

Table 2: The RMSFE for Forecast Horizons $\mathrm{h}=1,3,6$ and 12 for the Three VARs

\begin{tabular}{|l|l|c|c|c|}
\hline \multirow{2}{*}{ Horizons } & \multicolumn{1}{|c|}{ Variables } & SMALL & MEDIUM & LARGE BVAR \\
\hline \multirow{3}{*}{$\mathrm{h}=1$} & GDP_USA & 0.042222 & 0.060223 & 0.123261 \\
\cline { 2 - 5 } & HPI_USA & 0.052158 & 0.081442 & 0.220200 \\
\cline { 2 - 5 } & SI_USA & 0.530247 & 0.717384 & 0.791179 \\
\hline \multirow{3}{*}{$\mathrm{h}=3$} & GDP_USA & 0.907845 & 0.910629 & 1.072776 \\
\cline { 2 - 5 } & HPI_USA & 1.091275 & 1.103746 & 1.967154 \\
\cline { 2 - 5 } & SI_USA & 0.535300 & 0.570965 & 0.618733 \\
\hline \multirow{3}{*}{$\mathrm{h}=6$} & GDP_USA & 1.018012 & 1.095981 & 1.685852 \\
\cline { 2 - 5 } & HPI_USA & 1.509412 & 1.588623 & 0.720589 \\
\cline { 2 - 5 } & SI_USA & 0.531530 & 0.544320 & 2.202496 \\
\hline \multirow{3}{*}{$\mathrm{h}=12$} & GDP_USA & 1.167578 & 1.400305 & 2.324368 \\
\cline { 2 - 5 } & HPI_USA & 1.730941 & 1.741873 & 0.615186 \\
\cline { 2 - 5 } & SI_USA & 0.577833 & 0.580487 & \\
\hline
\end{tabular}

So, according to Table 2, we notice, that the smallest specification outperforms the largest one in terms of forecast accuracy. It seems that the smaller the model, the better the forecast. This confirms that the USA continues to retain its place as the world's principal leader, and does not depend on the other OECD countries. Moreover, it seems that the SMALL and MEDIUM VARs produce qualitatively and quantitatively similar results. This denotes that dealing with a LARGE VAR does not help to improve the forecast for any of the three U.S key variables considered. 


\subsubsection{Structural Analysis}

In this section, we present the results of the impulse response functions, and the variance decompositions to the U.S. housing price index shock in mid-2006 for the VARs.

We display the impulse response functions for the three models under consideration only for the three U.S. key variables (GDP_USA, HPI_USA, and SI_USA) included in the different VARs.

We divide the variables in the data into slow and fast-moving variables: the slow-moving ones are GDP, consumption, housing price index, CPI, industrial production, export and import of goods and services, and unemployment rate. The rest of the variables e.g. stock prices index, effective exchange rates, short-term and longterm interest rates are the fast-moving ones. Also, $r_{t}$ is the U.S. housing prices index.

The dotted lines indicate the posterior coverage intervals corresponding to $90 \%$ and $68 \%$ confidence levels as mentioned in the legend.

At first sight, we notice that the impulse responses maintain the expected sign. We remark that the smaller the VAR is, the tighter the $90 \%$ and $68 \%$ confidence intervals are, and vice versa.

For the SMALL VAR, the impulse responses are significant and become nil at about five-month horizon at the exception of the U.S GDP, where the initial shock is persistent for more than one year.

For the MEDIUM VAR, a positive American housing price shock immediately and significantly affects the U.S key variables. We notice that the sharp of the impulse responses are qualitatively the same as for the SMALL but more persistent except for the U.S GDP. The MEDIUM VAR produces a more realistic feature to the contagion effects during the subprime crisis.

For the LARGE VAR, the U.S impulse responses are not significant, for the whole one-year horizon considered, unlike the American housing prices. Unfortunately, the confidence bounds are wide denoting that the impulse responses are unreliable.

The relative tight confidence bounds of the SMALL and the MEDIUM VARs indicate the precision of the response of the U.S. housing prices index positive shock on the other three U.S key variables, which is not the case for the LARGE VAR. In fact, in the case of the last model, the 90 and $68 \%$ confidence bounds are very wide. So, it seems that the SMALL and MEDIUM models provide qualitatively the best results in terms of impulse response functions.

At this stage, combining these conclusions with the previous ones made in the case of forecasting analysis, leads us to say that the SMALL and MEDIUM VARs are preferable to the LARGE one.

Since the SMALL VAR is an interesting model, but, as mentioned by Bernanke and al. (2005), it is criticized due to its limited number of variables and to complete our analysis, we report the impulse response functions for the seventeen OECD housing prices in the case of the MEDIUM and LARGE VARs, respectively in figures 2 and 3. In fact, the advantage of the MEDIUM and LARGE VARs, compared to the SMALL one, is that impulse responses can be observed for all the OECD countries.

So, just as a confirmation of our previous findings, it appears, clearly, that the MEDIUM VAR is preferable to the LARGE one. This last model has very wide confidence bounds. For the MEDIUM VAR, we remark that the OECD housing markets have been significantly and immediately impacted by the initial shock but they did not react in the same way. So, the MEDIUM VAR enables us to obtain the responses of a large set of variables and this provides a more comprehensive picture of the effects of the subprime crisis. 
Figure 1: Impulse Response Functions for the three U.S. variables

(GDP_USA, HPI_USA and SI_USA) for the Three Models (SMALL, MEDIUM and LARGE VARs)

SMALL
GDP USA

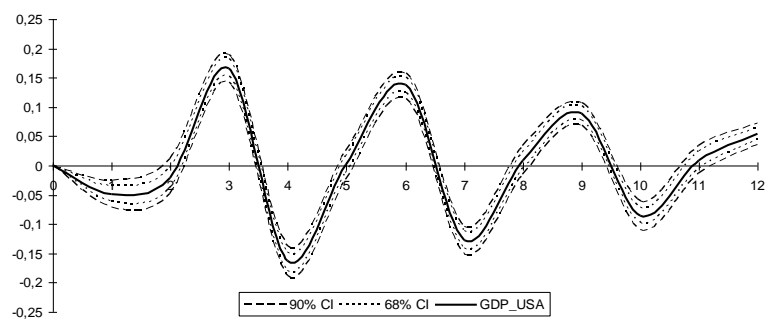

MEDIUM

GDP_USA

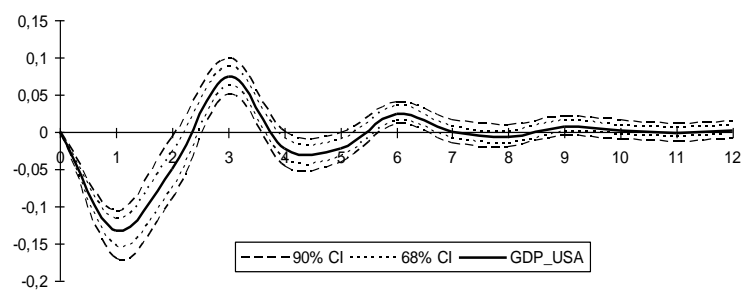

LARGE

GDP_USA
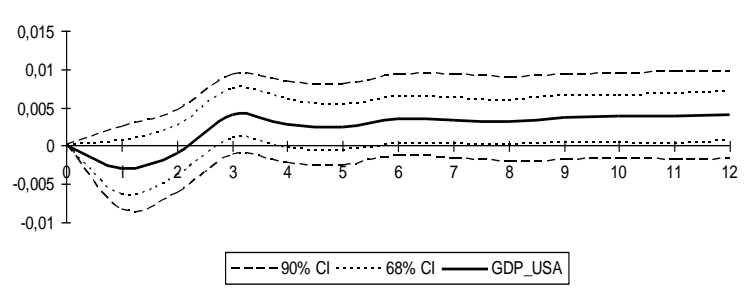

SMALL

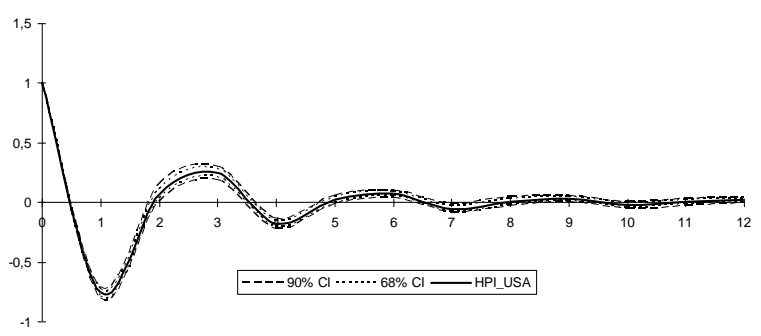

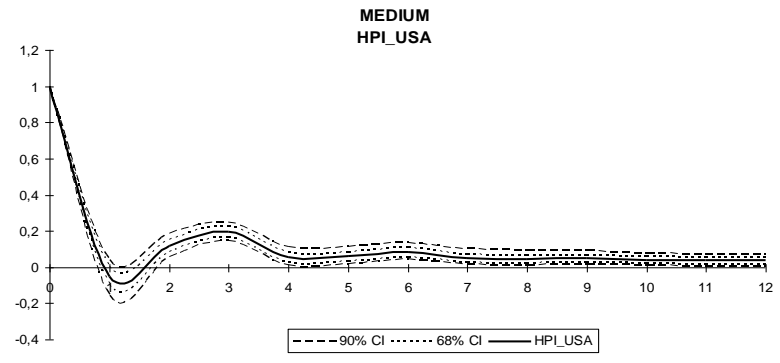

LARGE

HPI USA
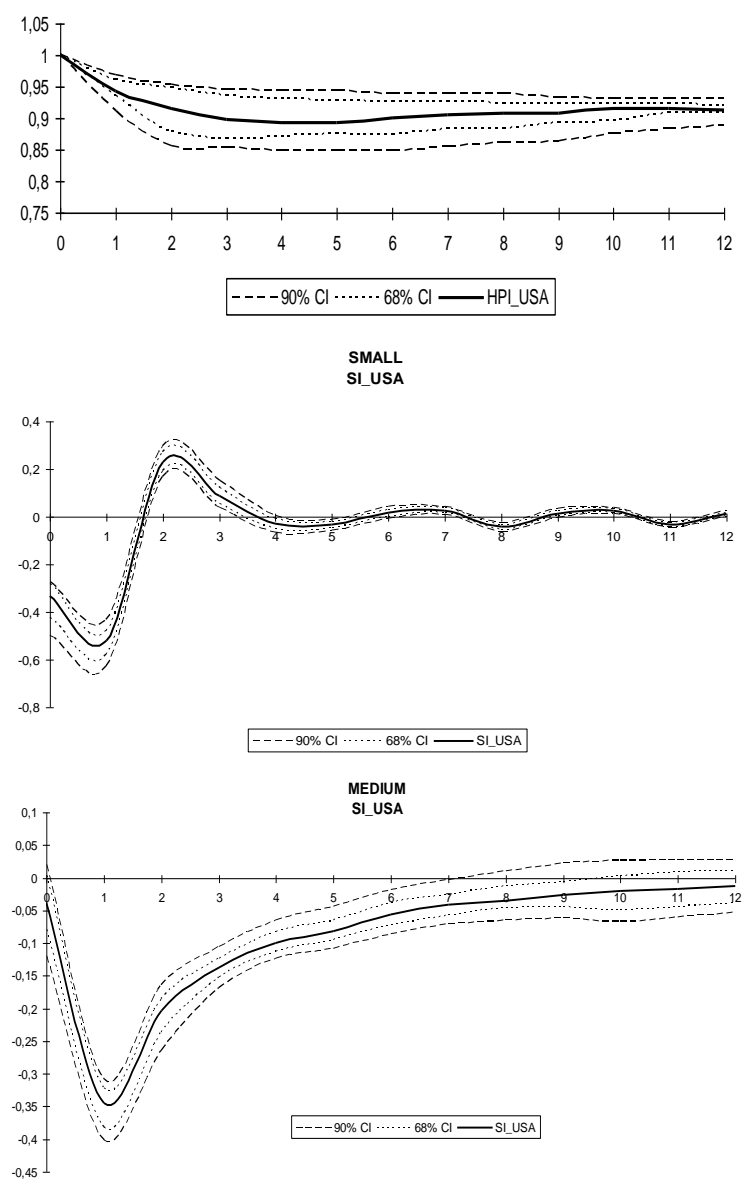

LARGE

SI_USA

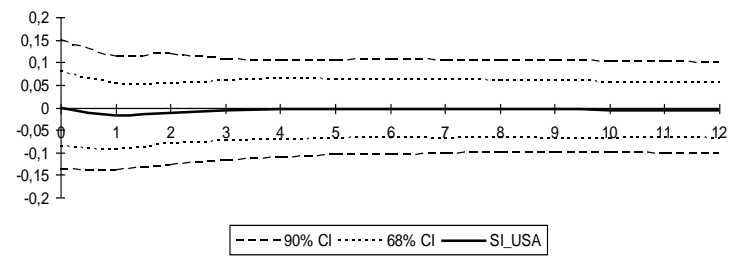


Figure 2: Impulse Response Functions of the Seventeen OECD Housing Price Indices for the MEDIUM VAR

MEDIUM

HPI_CAN

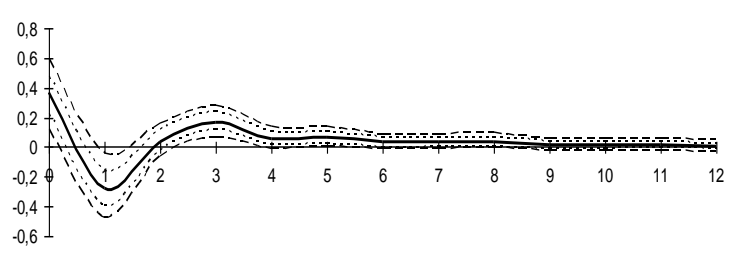

$----90 \% \mathrm{Cl} \cdots \cdots \cdot 68 \% \mathrm{Cl}$-HPI_CAN

MEDIUM

HPI_FIN

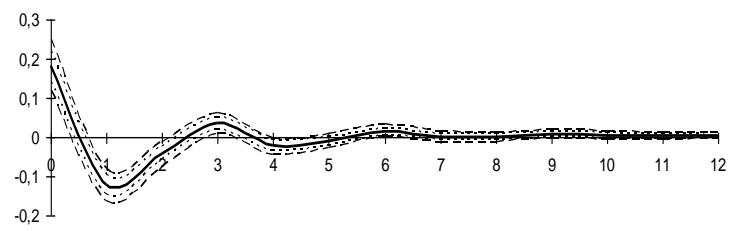

$----90 \% \mathrm{Cl} \cdots \cdots \cdot 68 \% \mathrm{Cl} \longrightarrow$ HPI_FIN

MEDIUM HPI_FRA

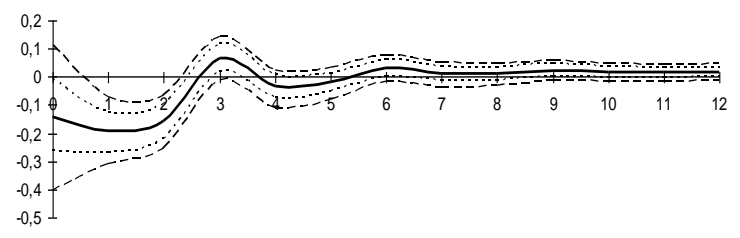

$----90 \% \mathrm{Cl} \cdots \cdots \cdot 68 \% \mathrm{Cl} \longrightarrow$ HPI_FRA

MEDIUM

HPI_ALL

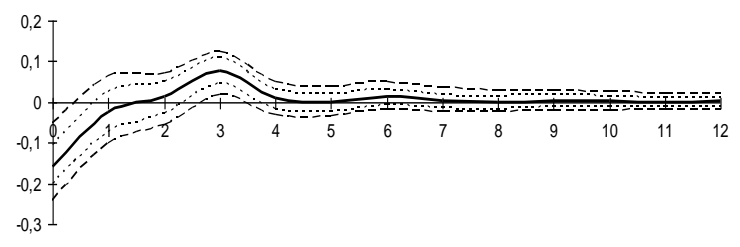

$----90 \% \mathrm{Cl} \cdots \cdots \cdot 68 \% \mathrm{Cl}$-HPI_ALL

MEDIUM

HPI_IRL

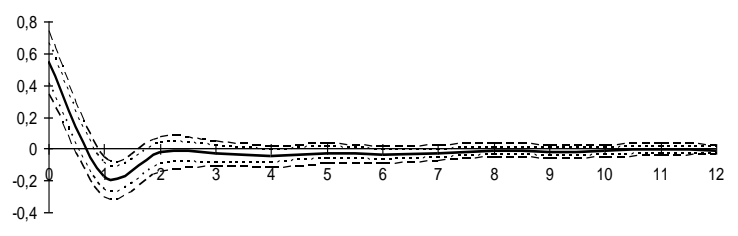

$----90 \% \mathrm{Cl} \cdots \cdots \cdot 68 \% \mathrm{Cl} \longrightarrow$ HPI_IRL
MEDIUM

HPI_ITA
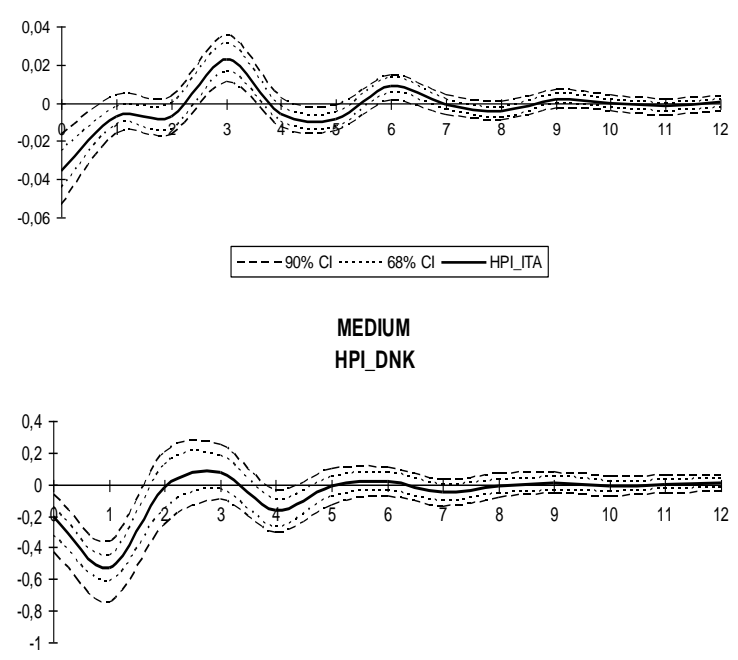

$----90 \% \mathrm{Cl} \cdots \cdots \cdot 68 \% \mathrm{Cl}$-HPI_DNK

MEDIUM

HPI_UK
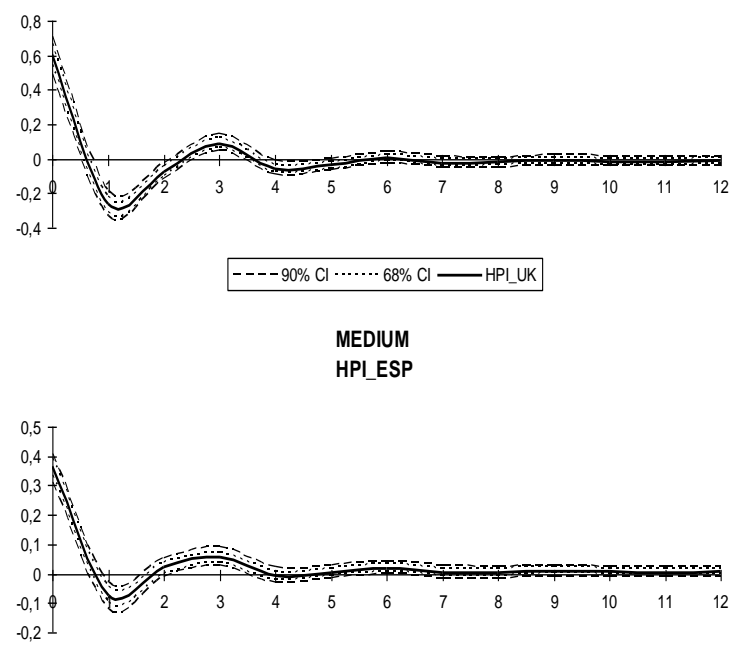

$----90 \% \mathrm{Cl} \cdots \cdots \cdot 68 \% \mathrm{Cl} \longrightarrow$ HPI_ESP

MEDIUM

HPI_SWI

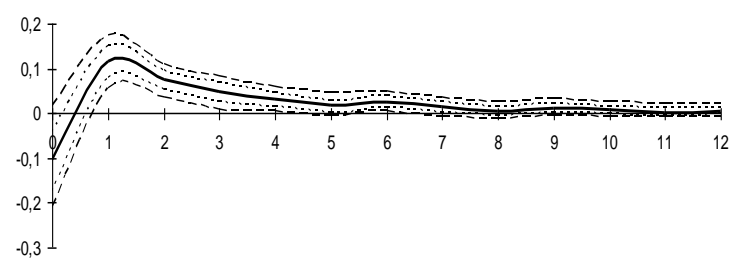

$----90 \% \mathrm{Cl} \cdots \cdots \cdot 68 \% \mathrm{Cl} \longrightarrow$ - HPISSWI 

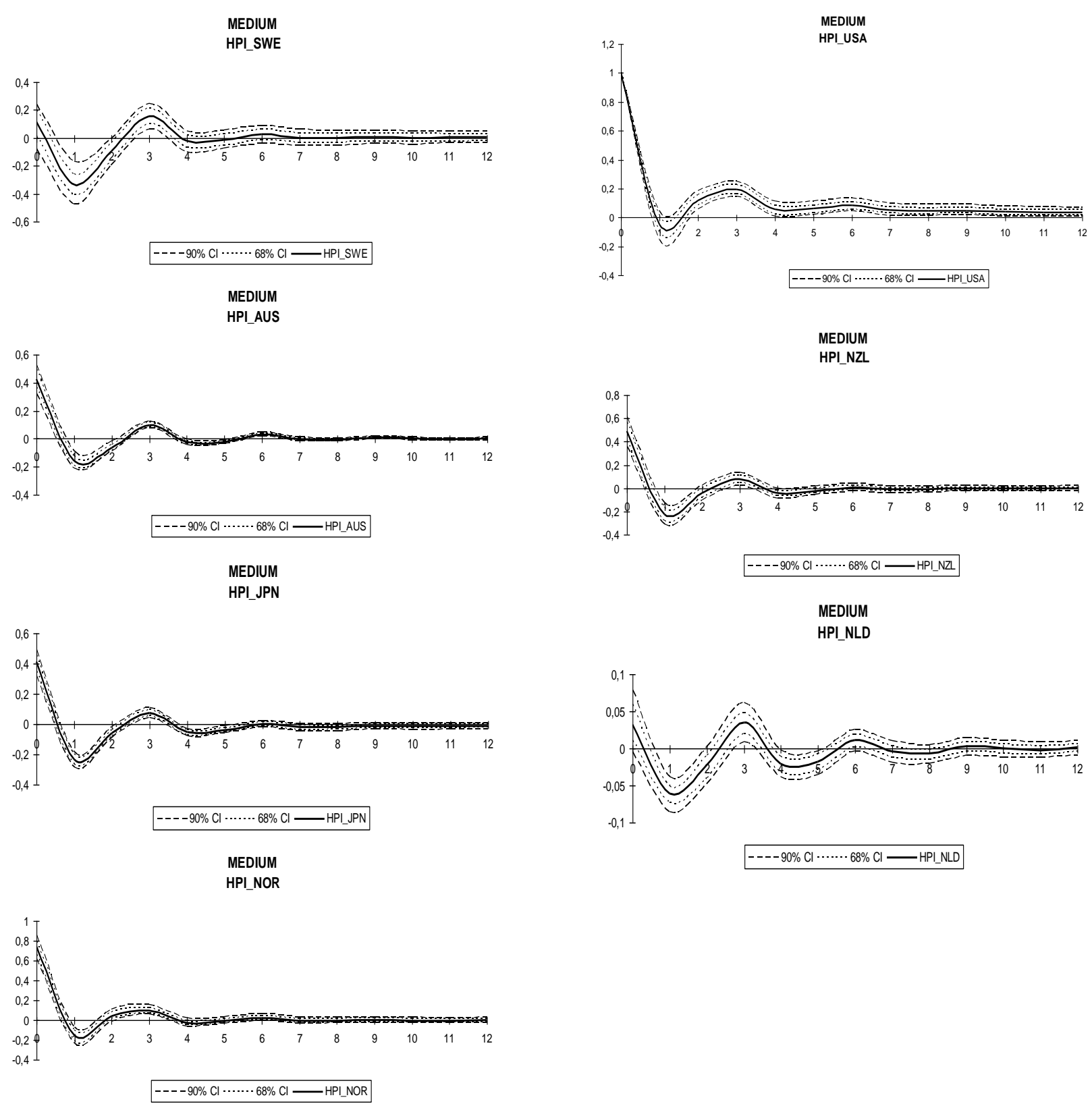
Figure 3: Impulse Response Functions for the Seventeen OECD Housing Price Indices for the LARGE VAR LARGE HPI_CAN

LARGE

HPL_IRL
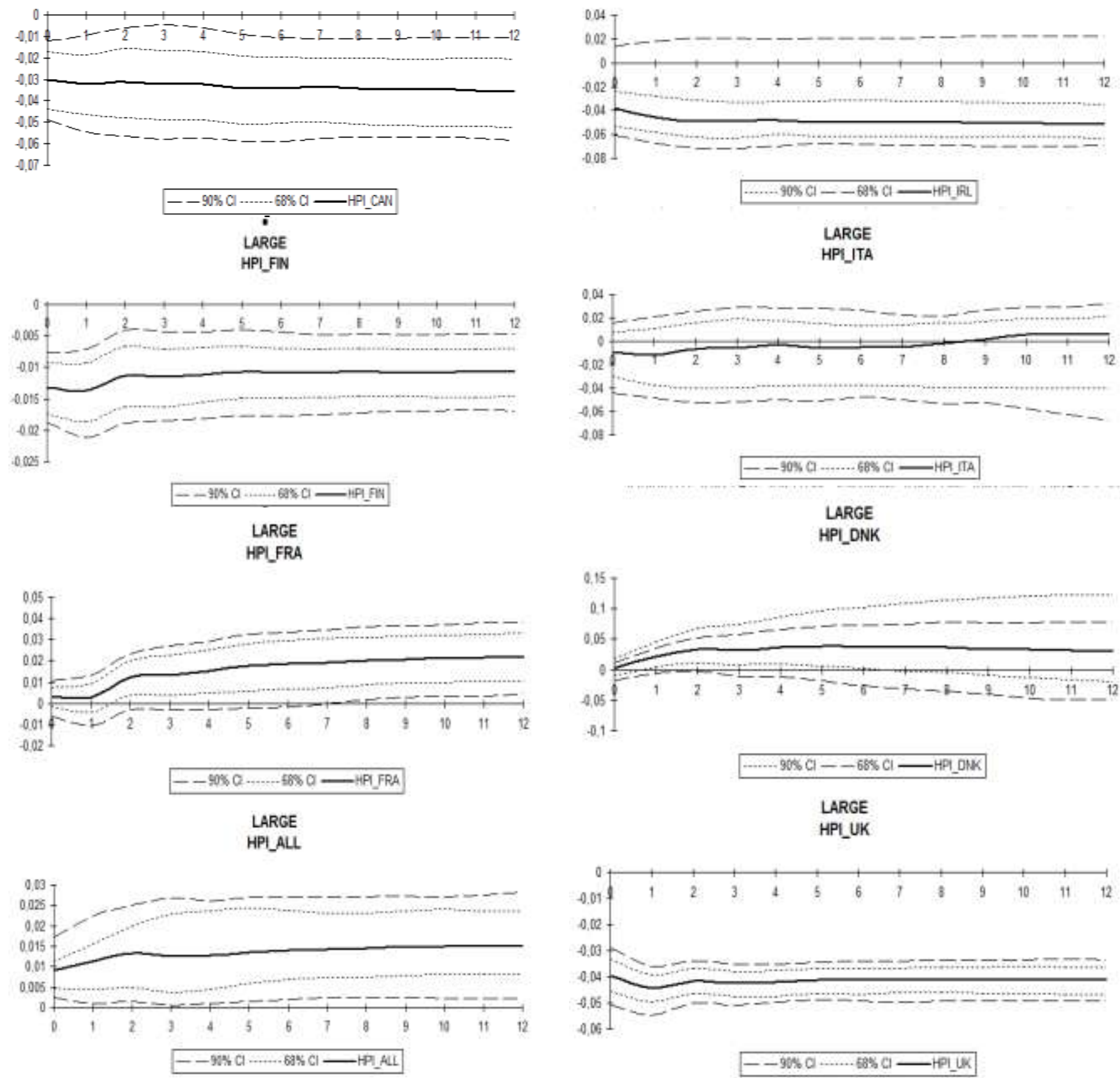


\section{LARGE \\ HPIESP}
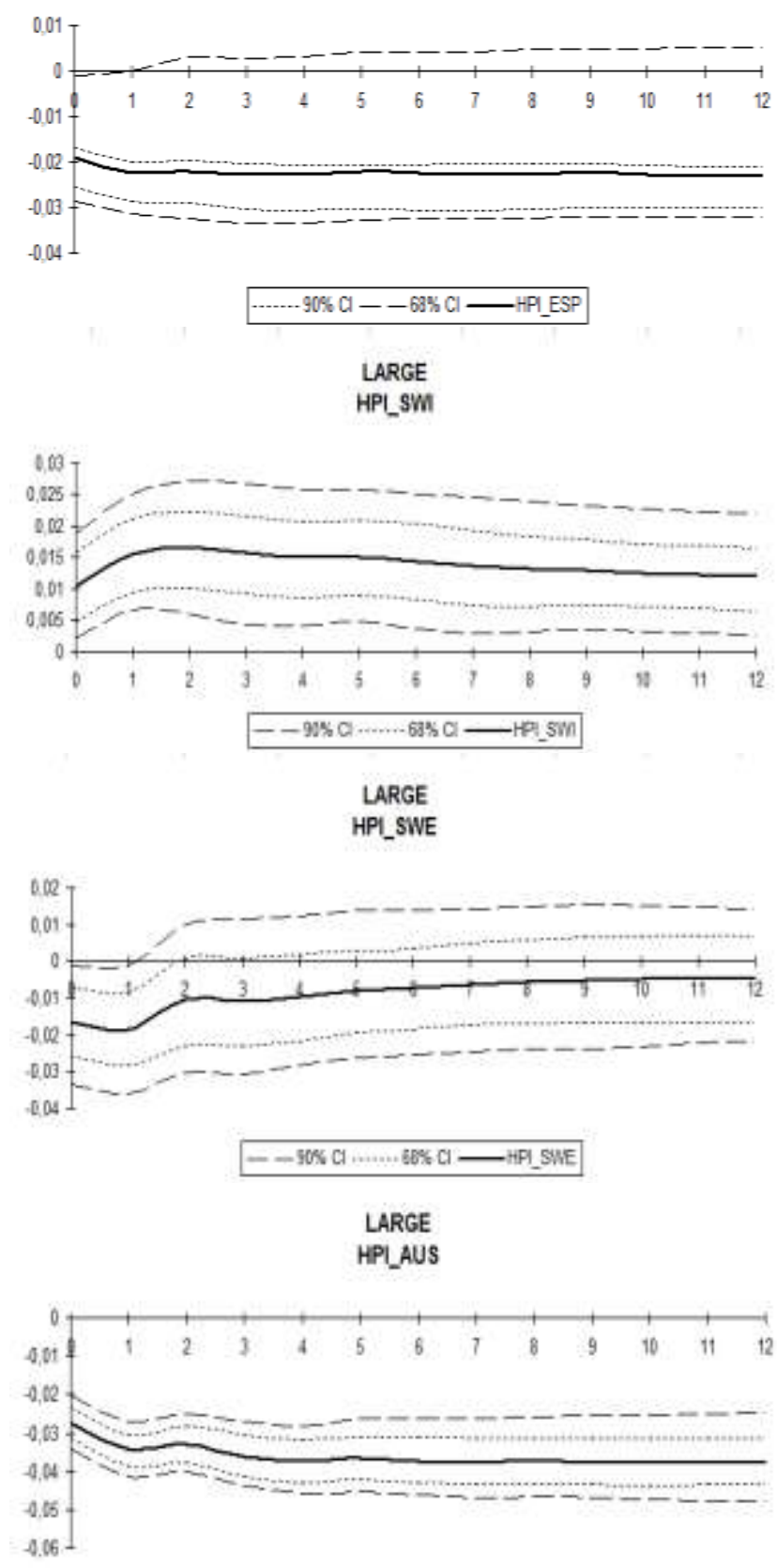

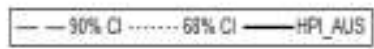
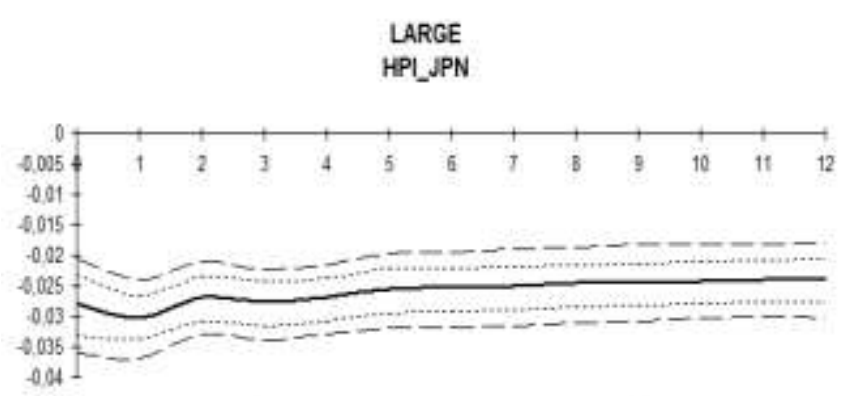

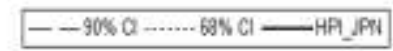

LARGE

HPI_NOR

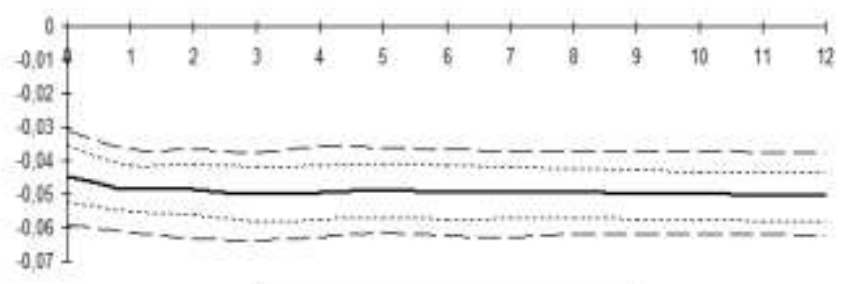

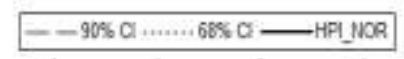

LARGE

HPINNZL
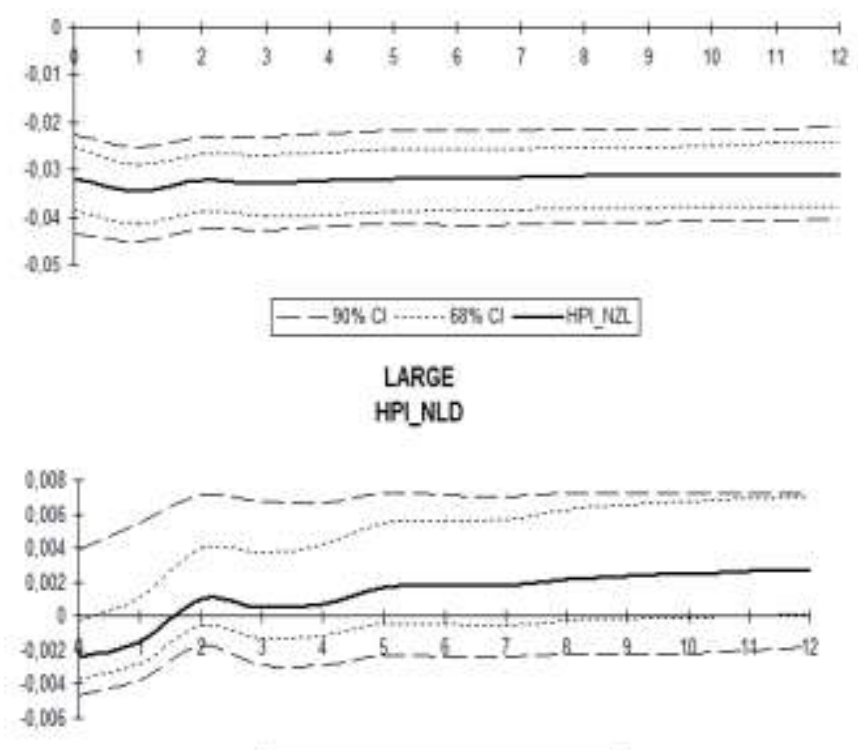

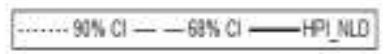




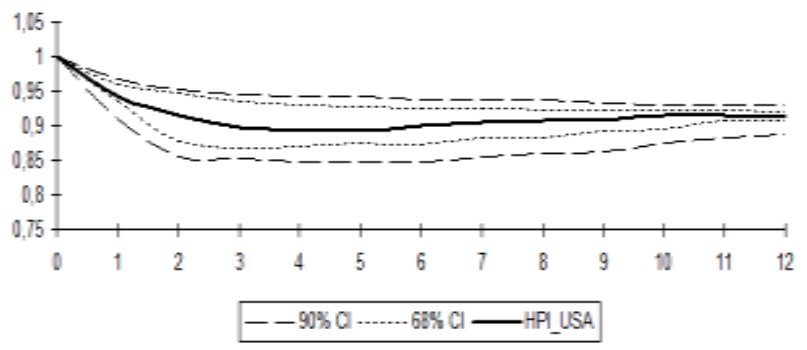

Consequently, the MEDIUM VAR provides realistic response functions reflecting what happened during the subprime crisis. This result is confirmed also by Kaabia and al. (2013).

Moreover, the same features can be seen from the variance decomposition analysis below:

Table 3: Percentage Share of the US Housing Price Index Shock in the Forecast Error Variance for different Forecast Horizons

\begin{tabular}{|c|c|c|c|c|}
\hline Variable & Horizon & SMALL & MEDIUM & LARGE \\
\hline \multirow{3}{*}{ GDP_USA } & 1 & 0 & 0 & 0 \\
\cline { 2 - 5 } & 3 & 0.9644 & 0.34672 & 0.00128 \\
\cline { 2 - 5 } & 6 & 12.18796 & 12.77802 & 0.00358 \\
\cline { 2 - 5 } & 12 & 18.28143 & 17.50771 & 0.00696 \\
\cline { 2 - 5 } & 1 & 94.93896 & 93.18396 & 8.76813 \\
\cline { 2 - 5 } & 3 & 93.37155 & 93.29603 & 19.17080 \\
\cline { 2 - 5 } & 12 & 92.90642 & 92.88318 & 30.58735 \\
\cline { 2 - 5 } & 1 & 92.69278 & 92.35931 & 45.48698 \\
\cline { 2 - 5 } & 3 & 5.457004 & 13.38062 & $7.71 \mathrm{E}-06$ \\
\cline { 2 - 5 } & 6 & 15.01895 & 13.42967 & 0.00244 \\
\cline { 2 - 5 } & 12 & 15.06545 & 13.30027 & 0.00219 \\
\hline
\end{tabular}

The results show that the size of the U.S housing price index shock is clearly more pronounced for the SMALL and MEDIUM models than for the LARGE one.

Besides, for three U.S key variables, and for all horizons, we remark that the size of the initial shock in the SMALL and MEDIUM VARs is bigger than that in the LARGE one.

This suggests that the U.S housing shock is more, and more persistent, even after a horizon of 12 months for the SMALL and MEDIUM VARs. The results show that the American key variables have been quickly affected, and that the size of the positive U.S. housing price index shock is clearly more pronounced for the SMALL and MEDIUM models than for the LARGE one. This is the same feature that we had when making the structural analysis using the MEDIUM VAR.

This finding confirms the previous ones in the case of the structural and forecast analysis denoting that the SMALL and MEDIUM VARs are preferable to the LARGE one. But since the SMALL VAR is criticized due to its limited number of variables, the MEDIUM VAR is a suitable model for international study.

It appears that the standard OLS estimation is interesting; however, the Bayesian shrinkage is a preferable useful tool in the case of an international contagion study allowing providing both a more comprehensive picture of the contagion effects as well as a more complete check of the empirical plausibility of the underlying specification. 


\section{CONCLUSION}

We study the contagion effects of a U.S. housing shock on OECD countries over the period of the subprime crisis. For that, we evaluate forecasting accuracy and perform a structural analysis exercise using VAR models of different sizes: a standard VAR estimated by OLS and a MEDIUM and LARGE VARs estimated by a Bayesian shrinkage procedure.

We took as point of departure the great criticism addressed especially by Bernanke and al. (2005) is the sparse information set of the VAR model which can only include a few variables to conserve degrees of freedom. So, we propose to study different-sized VAR models (SMALL, MEDIUM and LARGE). We consider the following specifications: 3, 19 and 204 international macroeconomic and financial variables.

We examine both forecasting accuracy and structural analysis of the effect of a positive U.S. housing price index shock on U.S key variables and OECD housing markets so as to try to replicate what has happened during the subprime crisis.

We find that the smallest specification outperforms the largest one in terms of forecast accuracy, and structural analysis. Moreover, the SMALL and MEDIUM VARs produce qualitatively similar results suggesting that the MEDIUM VAR is more successful at extracting pertinent information for a large data set. So, we conclude that the MEDIUM VAR permits us to obtain the responses of a large set of variables thus providing a more comprehensive picture of the effects of the subprime crisis.

It appears that the standard OLS estimation is interesting however the Bayesian shrinkage is a useful tool in the case of an international contagion study allowing providing both a more comprehensive picture of the contagion effects as well as a more complete check of the empirical plausibility of the underlying specification. These findings are in lines with those of Kaabia and al. (2013).

\section{AUTHOR INFORMATION}

Olfa Kaabia, EconomiX-CNRS (UMR 7235), University of Paris Ouest Nanterre La Defense, France. E-mail: olfa.kaabia@u-paris10.fr (Corresponding author)

Ilyes Abid, EconomiX-CNRS (UMR 7235), University of Paris Ouest Nanterre La Defense, France. E-mail: ilyes.abid@u-paris10.fr

\section{REFERENCES}

1. Banbura, M., Giannone, D. and Reichlin, L. (2010). "Large Bayesian vector auto regressions", Journal of Applied Econometrics, John Wiley \& Sons, Ltd., vol. 25(1), p. 71-92.

2. Bernanke, B., Boivin, J. and Eliasz, P. (2005). "Measuring the Effects of Monetary Policy: a Factor Augmented Vector Autoregressive (FAVAR) Approach", Quarterly Journal of Economics, February 2005.

3. Christiano, L. J., M. Eichenbaum, and C. Evans (1996). "The Effects of Monetary Policy Shocks: Evidence from the Flow of Funds", The Review of Economics and Statistics, 78(1), 16-34.

4. De Bandt, O. and Malik, S. (2010). "Is there Evidence of Shift-Contagion in International Housing Markets?", Working papers 295, Banque de France.

5. De Mol, C., D. Giannone and Reichlin L. (2008). "Forecasting using a large number of predictors: is Bayesian shrinkage a valid alternative to principal components?", Journal of Econometrics, Vol. 146 (2), pages 318-328.

6. Kaabia, O and Abid, I. (2013). "Theoretical Channels of International Transmission during the Subprime Crisis to OECD Countries: A FAVAR Model under Bayesian Framework", Journal of Applied Business Research, Vol. 29, 으 2, pp. 443-460.

7. Kaabia, O, Abid, I. and Guesmi, K. (2013). "Does Bayesian Shrinkage Help to better reflect what happened during the subprime crisis?", Economic Modelling, Vol. 31, pp. 423-432. 
8. Kadiyala, K. R., and Karlsson S. (1997). "Numerical Methods for Estimation and Inference in Bayesian VAR-Models", Journal of Applied Econometrics, 12(2), pages 99-132.

9. Kim, S. (2001). "International transmission of U.S. monetary policy shocks: Evidence from VAR's", Journal of Monetary Economics, 48(2), 339-372.

10. Koop, G. (2010). "Forecasting with Medium and Large Bayesian VARs," Working Paper Series 43_10, The Rimini Centre for Economic Analysis.

11. Leeper E. M., Sims C. A. and Zha Tao (1996). "What Does Monetary Policy Do?", Brookings Papers on Economic Activity, Economic Studies Program, The Brookings Institution, vol. 27(2), pages 1-78.

12. Litterman, R. (1986). "Forecasting With Bayesian Vector Autoregressions - Five Years of Experience", Journal of Business and Economic Statistics, vol. 4, pages 25-38.

13. Otrok, C. and Terrones, M. (2004). "The Global Housing Price Boom", IMF, World Economic Outlook, September.

14. Robertson J. C. and Tallman E. W. (1999). "Prior parameter uncertainty: Some implications for forecasting and policy analysis with VAR models," Working Paper 99-13, Federal Reserve Bank of Atlanta.

15. Sims, C. A. (1980). "Macroeconomics and Reality", Econometrica, Econometric Society, vol. 48(1), pages 1-48, January.

16. Sims Christopher A. and Zha, T. (1998). "Bayesian Methods for Dynamic Multivariate Models", International Economic Review, Department of Economics, University of Pennsylvania and Osaka University Institute of Social and Economic Research Association, vol. 39(4), pages 949-68, November.

17. Stock, J.H. and Watson, M.W. (2005), "Implications of Dynamic Factor Models for VAR Analysis", NBER, Working Paper, http://www.nber.org/papers/w11467. 


\section{APPENDIX: DATA TRANSFORMATIONS DETAILS}

As in Stock and Watson (2005a), we use the following transformation codes: 1 - no transformation (levels); 2 - first difference; 3 - second difference; 4 -logarithm; 5- first difference of logarithm and 6- second difference of logarithm.

In the transformation line, ln denotes logarithm, $\Delta \ln$ and $\Delta^{2} \ln$ denote the first and second difference of the logarithm, lv denotes the level of the series, and $\Delta \mathrm{lv}$ denotes the first difference of the series.

Also, following Bernanke and al. (2005), we divide the variables into slow moving (denoted by an asterisk: * next to the variable) and fast moving variables.

\begin{tabular}{|c|c|c|c|c|c|c|c|c|c|c|c|c|c|c|c|c|c|}
\hline Short Name & $\begin{array}{c}\text { USA } \\
\text { GDP* }\end{array}$ & $\begin{array}{l}\text { CAN } \\
\text { GDP* }\end{array}$ & $\begin{array}{c}\text { FIN } \\
\text { GDP* }\end{array}$ & $\begin{array}{c}\text { FRA } \\
\text { GDP* }\end{array}$ & $\begin{array}{c}\text { DEU } \\
\text { GDP* }\end{array}$ & $\begin{array}{c}\text { IRL } \\
\text { GDP* }\end{array}$ & $\begin{array}{c}\text { ITA } \\
\text { GDP* }\end{array}$ & $\begin{array}{l}\text { NLD } \\
\text { GDP* }\end{array}$ & $\begin{array}{c}\text { ESP } \\
\text { GDP* }\end{array}$ & $\begin{array}{c}\text { DNK } \\
\text { GDP* }\end{array}$ & $\begin{array}{l}\text { NOR } \\
\text { GDP* }\end{array}$ & $\begin{array}{c}\text { SWE } \\
\text { GDP* }\end{array}$ & $\begin{array}{c}\text { SWI } \\
\text { GDP* }\end{array}$ & $\begin{array}{c}\mathrm{UK} \\
\text { GDP* }\end{array}$ & $\begin{array}{c}\text { AUS } \\
\text { GDP* }\end{array}$ & $\begin{array}{c}\text { JPN } \\
\text { GDP* }\end{array}$ & $\begin{array}{c}\text { NZL } \\
\text { GDP* }\end{array}$ \\
\hline Transformation & $\Delta^{2} \ln$ & $\Delta^{2} \ln$ & $\Delta^{2} \ln$ & $\Delta^{2} \ln$ & $\Delta^{2} \ln$ & $\Delta^{2} \ln$ & $\Delta^{2} \ln$ & $\Delta^{2} \ln$ & $\Delta^{2} \ln$ & $\Delta^{2} \ln$ & $\Delta^{2} \ln$ & $\Delta^{2} \ln$ & $\Delta^{2} \ln$ & $\Delta^{2} \ln$ & $\Delta^{2} \ln$ & $\Delta^{2} \ln$ & $\Delta^{2} \ln$ \\
\hline CODE & 6 & 6 & 6 & 6 & 6 & 6 & 6 & 6 & 6 & 6 & 6 & 6 & 6 & 6 & 6 & 6 & 6 \\
\hline
\end{tabular}

\begin{tabular}{|c|c|c|c|c|c|c|c|c|c|c|c|c|c|c|c|c|c|}
\hline Short Name & $\begin{array}{c}\text { USA } \\
\text { CONS* }\end{array}$ & $\begin{array}{c}\text { CAN } \\
\text { CONS* }\end{array}$ & $\begin{array}{c}\text { FIN } \\
\text { CONS* }\end{array}$ & $\begin{array}{c}\text { FRA } \\
\text { CONS* }\end{array}$ & $\begin{array}{c}\text { DEU } \\
\text { CONS* }\end{array}$ & $\begin{array}{c}\text { IRL } \\
\text { CONS* }\end{array}$ & $\begin{array}{c}\text { ITA } \\
\text { CONS* }\end{array}$ & $\begin{array}{c}\text { NLD } \\
\text { CONS* }\end{array}$ & $\begin{array}{c}\text { ESP } \\
\text { CONS* }\end{array}$ & $\begin{array}{c}\text { DNK } \\
\text { CONS* }\end{array}$ & $\begin{array}{c}\text { NOR } \\
\text { CONS* }\end{array}$ & $\begin{array}{c}\text { SWE } \\
\text { CONS* }\end{array}$ & $\begin{array}{c}\text { SWI } \\
\text { CONS* }\end{array}$ & $\begin{array}{c}\text { UK } \\
\text { CONS* }\end{array}$ & $\begin{array}{c}\text { AUS } \\
\text { CONS* }\end{array}$ & $\begin{array}{c}\text { JPN } \\
\text { CONS* }\end{array}$ & $\begin{array}{c}\text { NZL } \\
\text { CONS* }\end{array}$ \\
\hline Transformation & $\Delta^{2} \ln$ & $\Delta^{2} \ln$ & $\Delta^{2} \ln$ & $\Delta^{2} \ln$ & $\Delta^{2} \ln$ & $\Delta^{2} \ln$ & $\Delta^{2} \ln$ & $\Delta^{2} \ln$ & $\Delta^{2} \ln$ & $\Delta^{2} \ln$ & $\Delta^{2} \ln$ & $\Delta^{2} \ln$ & $\Delta^{2} \ln$ & $\Delta^{2} \ln$ & $\Delta^{2} \ln$ & $\Delta^{2} \ln$ & $\Delta^{2} \ln$ \\
\hline CODE & 6 & 6 & 6 & 6 & 6 & 6 & 6 & 6 & 6 & 6 & 6 & 6 & 6 & 6 & 6 & 6 & 6 \\
\hline
\end{tabular}

\begin{tabular}{|l|c|c|c|c|c|c|c|c|c|c|c|c|c|c|c|c|c|}
\hline Short Name & $\begin{array}{c}\text { USA } \\
\text { HPI* }\end{array}$ & $\begin{array}{c}\text { CAN } \\
\text { HPI* }\end{array}$ & $\begin{array}{c}\text { FIN } \\
\text { HPI }\end{array}$ & $\begin{array}{c}\text { FRA } \\
\text { HPI* }\end{array}$ & $\begin{array}{c}\text { DEU } \\
\text { HPI* }\end{array}$ & $\begin{array}{c}\text { IRL } \\
\text { HPI* }\end{array}$ & $\begin{array}{c}\text { ITA } \\
\text { HPI* }\end{array}$ & $\begin{array}{c}\text { NLD } \\
\text { HPI* }\end{array}$ & $\begin{array}{c}\text { ESP } \\
\text { HPI* }\end{array}$ & $\begin{array}{c}\text { DNK } \\
\text { HPI* }\end{array}$ & $\begin{array}{c}\text { NOR } \\
\text { HPI* }\end{array}$ & $\begin{array}{c}\text { SWE } \\
\text { HPI* }\end{array}$ & $\begin{array}{c}\text { SWI } \\
\text { HPI* }^{*}\end{array}$ & $\begin{array}{c}\text { UK } \\
\text { HPI* }^{*}\end{array}$ & $\begin{array}{c}\text { AUS } \\
\text { HPI }^{*}\end{array}$ & $\begin{array}{c}\text { JPN } \\
\text { HPI }^{*}\end{array}$ & $\begin{array}{c}\text { NZL } \\
\text { HPI* }^{*}\end{array}$ \\
\hline Transformation & $\Delta^{2} \ln$ & $\Delta^{2} \ln$ & $\Delta^{2} \ln$ & $\Delta^{2} \ln$ & $\Delta^{2} \ln$ & $\Delta^{2} \ln$ & $\Delta^{2} \ln$ & $\Delta^{2} \ln$ & $\Delta^{2} \ln$ & $\Delta^{2} \ln$ & $\Delta^{2} \ln$ & $\Delta^{2} \ln$ & $\Delta^{2} \ln$ & $\Delta^{2} \ln$ & $\Delta^{2} \ln$ & $\Delta^{2} \ln$ & $\Delta^{2} \ln$ \\
\hline CODE & 6 & 6 & 6 & 6 & 6 & 6 & 6 & 6 & 6 & 6 & 6 & 6 & 6 & 6 & 6 & 6 & 6 \\
\hline
\end{tabular}

\begin{tabular}{|c|c|c|c|c|c|c|c|c|c|c|c|c|c|c|c|c|c|}
\hline Short Name & $\begin{array}{l}\text { USA } \\
\text { CPI* }\end{array}$ & $\begin{array}{l}\text { CAN } \\
\text { CPI }\end{array}$ & $\begin{array}{c}\text { FIN } \\
\text { CPI* }\end{array}$ & $\begin{array}{l}\text { FRA } \\
\text { CPI* }\end{array}$ & $\begin{array}{l}\text { DEU } \\
\text { CPI }\end{array}$ & $\begin{array}{c}\text { IRL } \\
\text { CPI* }\end{array}$ & $\begin{array}{l}\text { ITA } \\
\text { CPI* }\end{array}$ & $\begin{array}{l}\text { NLD } \\
\text { CPI }^{*}\end{array}$ & $\begin{array}{l}\text { ESP } \\
\text { CPI* }\end{array}$ & $\begin{array}{l}\text { DNK } \\
\text { CPI* }\end{array}$ & $\begin{array}{l}\text { NOR } \\
\text { CPI* }\end{array}$ & $\begin{array}{l}\text { SWE } \\
\text { CPI* }\end{array}$ & $\begin{array}{l}\text { SWI } \\
\text { CPI* }\end{array}$ & $\begin{array}{c}\mathrm{UK} \\
\mathrm{CPI}^{*}\end{array}$ & $\begin{array}{l}\text { AUS } \\
\text { CPI* }\end{array}$ & $\begin{array}{c}\text { JPN } \\
\text { CPI* }\end{array}$ & $\begin{array}{l}\text { NZL } \\
\text { CPI* }\end{array}$ \\
\hline Transformation & $\Delta^{2} \ln$ & $\Delta^{2} \ln$ & $\Delta^{2} \ln$ & $\Delta^{2} \ln$ & $\Delta^{2} \ln$ & $\Delta^{2} \ln$ & $\Delta^{2} \ln$ & $\Delta^{2} \ln$ & $\Delta^{2} \ln$ & $\Delta^{2} \ln$ & $\Delta^{2} \ln$ & $\Delta^{2} \ln$ & $\Delta^{2} \ln$ & $\Delta^{2} \ln$ & $\Delta^{2} \ln$ & $\Delta^{2} \ln$ & $\Delta^{2} \ln$ \\
\hline CODE & 6 & 6 & 6 & 6 & 6 & 6 & 6 & 6 & 6 & 6 & 6 & 6 & 6 & 6 & 6 & 6 & 6 \\
\hline
\end{tabular}

\begin{tabular}{|c|c|c|c|c|c|c|c|c|c|c|c|c|c|c|c|c|c|}
\hline Short Name & $\begin{array}{c}\text { USA } \\
\text { PI* }^{*}\end{array}$ & $\begin{array}{c}\text { CAN } \\
\text { PI* }^{*}\end{array}$ & $\begin{array}{l}\text { FIN } \\
\text { PI* }^{*}\end{array}$ & $\begin{array}{l}\text { FRA } \\
\text { PI* }^{*}\end{array}$ & $\begin{array}{c}\text { DEU } \\
\text { PI* }^{*}\end{array}$ & $\begin{array}{l}\text { IRL } \\
\text { PI* }\end{array}$ & $\begin{array}{l}\text { ITA } \\
\text { PI* }\end{array}$ & $\begin{array}{l}\text { NLD } \\
\mathrm{PI}^{*}\end{array}$ & $\begin{array}{l}\text { ESP } \\
\text { PI* }^{*}\end{array}$ & $\begin{array}{c}\text { DNK } \\
\text { PI* }^{*}\end{array}$ & $\begin{array}{c}\text { NOR } \\
\mathrm{PI}^{*}\end{array}$ & $\begin{array}{l}\text { SWE } \\
\text { PI* }^{*}\end{array}$ & $\begin{array}{l}\text { SWI } \\
\mathrm{PI}^{*}\end{array}$ & $\begin{array}{l}\text { UK } \\
\text { PI* }\end{array}$ & $\begin{array}{c}\text { AUS } \\
\text { PI* }^{*}\end{array}$ & $\begin{array}{c}\text { JPN } \\
\text { PI* }^{*}\end{array}$ & $\begin{array}{l}\text { NZL } \\
\mathrm{PI}^{*}\end{array}$ \\
\hline Transformation & $\Delta \ln$ & $\Delta \ln$ & $\Delta \ln$ & $\Delta \ln$ & $\Delta \ln$ & $\Delta \ln$ & $\Delta \ln$ & $\Delta \ln$ & $\Delta \ln$ & $\Delta \ln$ & $\Delta \ln$ & $\Delta \ln$ & $\Delta \ln$ & $\Delta \ln$ & $\Delta \ln$ & $\Delta \ln$ & $\Delta \ln$ \\
\hline CODE & 5 & 5 & 5 & 5 & 5 & 5 & 5 & 5 & 5 & 5 & 5 & 5 & 5 & 5 & 5 & 5 & 5 \\
\hline
\end{tabular}




\begin{tabular}{|c|c|c|c|c|c|c|c|c|c|c|c|c|c|c|c|c|c|}
\hline Short Name & $\begin{array}{c}\text { USA } \\
\text { export* }\end{array}$ & \begin{tabular}{|c|} 
CAN \\
export*
\end{tabular} & $\begin{array}{c}\text { FIN } \\
\text { export* }\end{array}$ & $\begin{array}{c}\text { FRA } \\
\text { export* }\end{array}$ & $\begin{array}{c}\text { DEU } \\
\text { export* }\end{array}$ & $\begin{array}{c}\text { IRL } \\
\text { export* }\end{array}$ & $\begin{array}{c}\text { ITA } \\
\text { export* }\end{array}$ & $\begin{array}{l}\text { NLD } \\
\text { export* }\end{array}$ & $\begin{array}{c}\text { ESP } \\
\text { export* }\end{array}$ & $\begin{array}{c}\text { DNK } \\
\text { export* }\end{array}$ & $\begin{array}{c}\text { NOR } \\
\text { export* }\end{array}$ & $\begin{array}{c}\text { SWE } \\
\text { export* }\end{array}$ & $\begin{array}{c}\text { SWI } \\
\text { export* }\end{array}$ & $\begin{array}{c}\text { UK } \\
\text { export* }\end{array}$ & $\begin{array}{c}\text { AUS } \\
\text { export* }\end{array}$ & $\begin{array}{c}\text { JPN } \\
\text { export* }\end{array}$ & $\begin{array}{c}\text { NZL } \\
\text { export* }\end{array}$ \\
\hline transformation & $\Delta \ln$ & $\Delta \ln$ & $\Delta \ln$ & $\Delta \ln$ & $\Delta \ln$ & $\Delta \ln$ & $\Delta \ln$ & $\Delta \ln$ & $\Delta \ln$ & $\Delta \ln$ & $\Delta \ln$ & $\Delta \ln$ & $\Delta \ln$ & $\Delta \ln$ & $\Delta \ln$ & $\Delta \ln$ & $\Delta \ln$ \\
\hline CODE & 5 & 5 & 5 & 5 & 5 & 5 & 5 & 5 & 5 & 5 & 5 & 5 & 5 & 5 & 5 & 5 & 5 \\
\hline Short Name & $\begin{array}{c}\text { USA } \\
\text { import* }\end{array}$ & \begin{tabular}{|c|}
$\begin{array}{c}\text { CAN } \\
\text { import* }\end{array}$ \\
\end{tabular} & \begin{tabular}{|c|}
$\begin{array}{c}\text { FIN } \\
\text { import* }\end{array}$ \\
\end{tabular} & $\begin{array}{c}\text { FRA } \\
\text { import* }\end{array}$ & $\begin{array}{c}\text { DEU } \\
\text { import* }\end{array}$ & $\begin{array}{c}\text { IRL } \\
\text { import* }\end{array}$ & \begin{tabular}{|c|} 
ITA \\
import*
\end{tabular} & \begin{tabular}{|c|}
$\begin{array}{c}\text { NLD } \\
\text { import* }\end{array}$ \\
\end{tabular} & \begin{tabular}{|c|}
$\begin{array}{c}\text { ESP } \\
\text { import* }\end{array}$ \\
\end{tabular} & \begin{tabular}{|c|} 
DNK \\
import*
\end{tabular} & \begin{tabular}{|c|}
$\begin{array}{c}\text { NOR } \\
\text { import* }\end{array}$ \\
\end{tabular} & \begin{tabular}{|c|}
$\begin{array}{c}\text { SWE } \\
\text { import* }\end{array}$ \\
\end{tabular} & \begin{tabular}{|c|}
$\begin{array}{c}\text { SWI } \\
\text { import* }\end{array}$ \\
\end{tabular} & $\begin{array}{c}\text { UK } \\
\text { import* }\end{array}$ & $\begin{array}{c}\text { AUS } \\
\text { import* }\end{array}$ & \begin{tabular}{|c|} 
JPN \\
import*
\end{tabular} & \begin{tabular}{|c|}
$\begin{array}{c}\text { NZL } \\
\text { import* }\end{array}$ \\
\end{tabular} \\
\hline transformation & $\Delta \ln$ & $\Delta \ln$ & $\Delta \ln$ & $\Delta \ln$ & $\Delta \ln$ & $\Delta \ln$ & $\Delta \ln$ & $\Delta \ln$ & $\Delta \ln$ & $\Delta \ln$ & $\Delta \ln$ & $\Delta \ln$ & $\Delta \ln$ & $\Delta \ln$ & $\Delta \ln$ & $\Delta \ln$ & $\Delta \ln$ \\
\hline CODE & 5 & 5 & 5 & 5 & 5 & 5 & 5 & 5 & 5 & 5 & 5 & 5 & 5 & 5 & 5 & 5 & 5 \\
\hline Short Name & $\begin{array}{c}\text { USA } \\
\text { iTB_3 }\end{array}$ & $\begin{array}{l}\text { CAN } \\
\text { iTB_3 }\end{array}$ & $\begin{array}{c}\text { FIN } \\
\text { iTB_3 }\end{array}$ & $\begin{array}{l}\text { FRA } \\
\text { iTB_3 }\end{array}$ & $\begin{array}{c}\text { DEU } \\
\text { iTB_3 }\end{array}$ & $\begin{array}{c}\text { IRL } \\
\text { iTB_3 }\end{array}$ & $\begin{array}{c}\text { ITA } \\
\text { iTB_3 }\end{array}$ & $\begin{array}{c}\text { NLD } \\
\text { iTB_3 }\end{array}$ & $\begin{array}{c}\text { ESP } \\
\text { iTB_3 }\end{array}$ & $\begin{array}{c}\text { DNK } \\
\text { iTB_3 }\end{array}$ & $\begin{array}{c}\text { NOR } \\
\text { iTB_3 }\end{array}$ & $\begin{array}{c}\text { SWE } \\
\text { iTB_3 }\end{array}$ & $\begin{array}{c}\text { SWI } \\
\text { iTB_3 }\end{array}$ & $\begin{array}{c}\text { UK } \\
\text { iTB_3 }\end{array}$ & $\begin{array}{c}\text { AUS } \\
\text { iTB_3 }\end{array}$ & $\begin{array}{c}\text { JPN } \\
\text { iTB_3 }\end{array}$ & $\begin{array}{c}\text { NZL } \\
\text { iTB_3 }\end{array}$ \\
\hline transfor & $\Delta \mathrm{lv}$ & $\Delta \mathrm{lv}$ & $\Delta \mathrm{lv}$ & $\Delta \mathrm{lv}$ & $\Delta \mathrm{lv}$ & $\Delta \mathrm{lv}$ & $\Delta \mathrm{lv}$ & $\Delta \mathrm{lv}$ & $\Delta \mathrm{lv}$ & $\Delta \mathrm{lv}$ & $\Delta \mathrm{lv}$ & $\Delta \mathrm{lv}$ & $\Delta \mathrm{lv}$ & $\Delta \mathrm{lv}$ & $\Delta \mathrm{lv}$ & $\Delta \mathrm{lv}$ & $\Delta \mathrm{lv}$ \\
\hline CODE & 2 & 2 & 2 & 2 & 2 & 2 & 2 & 2 & 2 & 2 & 2 & 2 & 2 & 2 & 2 & 2 & 2 \\
\hline Short & \begin{tabular}{|c|} 
USA \\
iBond 10
\end{tabular} & \begin{tabular}{|c|} 
CAN \\
iBond 10
\end{tabular} & \begin{tabular}{|c|} 
FIN \\
iBond 10
\end{tabular} & \begin{tabular}{|c|} 
FRA \\
iBond 10
\end{tabular} & $\begin{array}{c}\text { DEU } \\
\text { iBond } 10\end{array}$ & \begin{tabular}{|c|} 
IRL \\
iBond 10
\end{tabular} & \begin{tabular}{|c|} 
ITA \\
iBond 10
\end{tabular} & \begin{tabular}{|c|} 
NLD \\
iBond 10
\end{tabular} & \begin{tabular}{|c|} 
ESP \\
iBond 10
\end{tabular} & $\begin{array}{c}\text { DNK } \\
\text { iBond } 10\end{array}$ & \begin{tabular}{|c|} 
NOR \\
iBond 10
\end{tabular} & \begin{tabular}{|c|} 
SWE \\
iBond 10
\end{tabular} & \begin{tabular}{|c|} 
SWI \\
iBond 10
\end{tabular} & \begin{tabular}{|c|} 
UK \\
iBond 10
\end{tabular} & $\begin{array}{c}\text { AUS } \\
\text { iBond } 10\end{array}$ & \begin{tabular}{|c|} 
JPN \\
iBond 10
\end{tabular} & \begin{tabular}{|c|} 
NZL \\
iBond 10
\end{tabular} \\
\hline transf & $\Delta \mathrm{lv}$ & $\Delta \mathrm{lv}$ & $\Delta \mathrm{lv}$ & $\Delta \mathrm{lv}$ & $\Delta \mathrm{lv}$ & $\Delta \mathrm{lv}$ & $\Delta \mathrm{lv}$ & $\Delta \mathrm{lv}$ & $\Delta \mathrm{lv}$ & $\Delta \mathrm{lv}$ & $\Delta \mathrm{lv}$ & $\Delta \mathrm{lv}$ & $\Delta \mathrm{lv}$ & $\Delta \mathrm{lv}$ & $\Delta \mathrm{lv}$ & $\Delta \mathrm{lv}$ & $\Delta \mathrm{lv}$ \\
\hline CODE & 2 & 2 & 2 & 2 & 2 & 2 & 2 & 2 & 2 & 2 & 2 & 2 & 2 & 2 & 2 & 2 & 2 \\
\hline Short Name & $\begin{array}{l}\text { USA } \\
\text { tx chg }\end{array}$ & $\begin{array}{l}\text { CAN } \\
\text { tx chg }\end{array}$ & $\begin{array}{c}\text { FIN } \\
\text { tx chg }\end{array}$ & $\begin{array}{l}\text { FRA } \\
\text { tx chg }\end{array}$ & $\begin{array}{l}\text { DEU } \\
\text { tx chg }\end{array}$ & $\begin{array}{c}\text { IRL } \\
\text { tx chg }\end{array}$ & $\begin{array}{c}\text { ITA } \\
\text { tx chg }\end{array}$ & $\begin{array}{l}\text { NLD } \\
\text { tx chg }\end{array}$ & $\begin{array}{c}\text { ESP } \\
\text { tx chg }\end{array}$ & $\begin{array}{l}\text { DNK } \\
\text { tx chg }\end{array}$ & $\begin{array}{l}\text { NOR } \\
\text { tx chg }\end{array}$ & $\begin{array}{l}\text { SWE } \\
\text { tx chg }\end{array}$ & $\begin{array}{c}\text { SWI } \\
\text { tx chg }\end{array}$ & $\begin{array}{c}\text { UK } \\
\text { tx chg }\end{array}$ & $\begin{array}{l}\text { AUS } \\
\text { tx chg }\end{array}$ & $\begin{array}{c}\text { JPN } \\
\text { tx chg }\end{array}$ & $\begin{array}{l}\text { NZL } \\
\text { tx chg }\end{array}$ \\
\hline transformation & $\Delta \ln$ & $\Delta \ln$ & $\Delta \ln$ & $\Delta \ln$ & $\Delta \ln$ & $\Delta \ln$ & $\Delta \ln$ & $\Delta \ln$ & $\Delta \ln$ & $\Delta \ln$ & $\Delta \ln$ & $\Delta \ln$ & $\Delta \ln$ & $\Delta \ln$ & $\Delta \ln$ & $\Delta \ln$ & $\Delta \ln$ \\
\hline CODE & 5 & 5 & 5 & 5 & 5 & 5 & 5 & 5 & 5 & 5 & 5 & 5 & 5 & 5 & 5 & 5 & 5 \\
\hline Short Name & USA SI & CAN SI & FIN SI & FRA SI & DEU SI & IRL SI & ITA SI & NLD SI & ESP SI & DNK SI & NOR SI & SWE SI & SWI SI & UK SI & AUS SI & JPN SI & NZL SI \\
\hline transfor & $\Delta \ln$ & $\Delta \ln$ & $\Delta \ln$ & $\Delta \ln$ & $\Delta \ln$ & $\Delta \ln$ & $\Delta \ln$ & $\Delta \ln$ & $\Delta \ln$ & $\Delta \ln$ & $\Delta \ln$ & $\Delta \ln$ & $\Delta \ln$ & $\Delta \ln$ & $\Delta \ln$ & $\Delta \ln$ & $\Delta \ln$ \\
\hline CODE & 5 & 5 & 5 & 5 & 5 & 5 & 5 & 5 & 5 & 5 & 5 & 5 & 5 & 5 & 5 & 5 & 5 \\
\hline Short & $\begin{array}{c}\text { USA } \\
\text { Unemp* }\end{array}$ & \begin{tabular}{|c|} 
CAN \\
Unemp*
\end{tabular} & $\begin{array}{c}\text { FIN } \\
\text { Unemp* }\end{array}$ & $\begin{array}{c}\text { FRA } \\
\text { Unemp* }\end{array}$ & $\begin{array}{c}\text { DEU } \\
\text { Unemp* }\end{array}$ & $\begin{array}{c}\text { IRL } \\
\text { Unemp* }\end{array}$ & $\begin{array}{c}\text { ITA } \\
\text { Unemp* }\end{array}$ & $\begin{array}{c}\text { NLD } \\
\text { Unemp* }\end{array}$ & $\begin{array}{c}\text { ESP } \\
\text { Unemp* }\end{array}$ & $\begin{array}{c}\text { DNK } \\
\text { Unemp* }\end{array}$ & $\begin{array}{c}\text { NOR } \\
\text { Unemp* }\end{array}$ & $\begin{array}{c}\text { SWE } \\
\text { Unemp* }\end{array}$ & $\begin{array}{c}\text { SWI } \\
\text { Unemp* }\end{array}$ & $\begin{array}{c}\text { UK } \\
\text { Unemp* }\end{array}$ & $\begin{array}{c}\text { AUS } \\
\text { Unemp* }\end{array}$ & $\begin{array}{c}\text { JPN } \\
\text { Unemp* }\end{array}$ & $\begin{array}{c}\text { NZL } \\
\text { Unemp* }\end{array}$ \\
\hline transforı & $\Delta \mathrm{lv}$ & $\Delta \mathrm{lv}$ & $\Delta \mathrm{lv}$ & $\Delta^{2} \mathrm{lv}$ & $\Delta^{2} \mathrm{lv}$ & $\Delta^{2} \mathrm{ll}$ & $\Delta^{2} \mathrm{ll}$ & $\Delta^{2} \mathrm{ll}$ & $\Delta^{2} \mathrm{lv}$ & $\Delta^{2} \mathrm{ll}$ & $\Delta \mathrm{lv}$ & $\Delta \mathrm{lv}$ & $\Delta \mathrm{lv}$ & $\Delta^{2} \mathrm{ll}$ & $\Delta \mathrm{lv}$ & $\Delta \mathrm{lv}$ & $\Delta \mathrm{lv}$ \\
\hline$\overline{\mathrm{CODE}}$ & 2 & 2 & 2 & 3 & 3 & 3 & 3 & 3 & 3 & 3 & 2 & 2 & 2 & 3 & 2 & 2 & 2 \\
\hline
\end{tabular}

Notes: The abbreviations GDP (Gross Domestic Product), CONS (Personal Consumption), HPI (Housing Price Index), CPI (Consumer Price Index), PI (Industrial Production), iTB_3 (3-Month Interest Rates), iBond 10 (10-year Government Bond Index), tx change (Effective Exchange rate), SI (Stock Index) and Unemp (Unemployment rate). 